\title{
Dwelling Fire Safety Evacuation (DFSE): A Conceptual Approach
}

\author{
Nurul Ayuni Abdul Aziz ${ }^{1,}$, Rumaizah Mohd Nordin ${ }^{1 *}$, Zulhabri Ismail ${ }^{1}$ Julitta Yunus $^{l}$, and Norfashiha Hashim ${ }^{1}$ \\ ${ }^{1}$ Faculty of Architecture, Planning and Surveying, Universiti Teknologi MARA, 40150 Shah Alam, Selangor, Malaysia
}

\begin{abstract}
Fire ignition needs three elements consisting of heat, oxygen and fuel that may lead to a significant threat to life and property, in urban and rural areas. Various researches have produced statistics on fire breakouts around the globe that paid attention to residential fire. In the case of Malaysia, residential or dwellings have contributed to increased fire casualties especially related to the accidental fire that was caused by electrical origins, cooking appliances, faulty or misuse of equipment, careless handling of fire or hot substances as well as negligence. Due to that fact, the most critical features of safety in building in the fire event is evacuation or probability of safe escape. Building Information Modelling (BIM) can be utilized as it is effectively making sure that the evacuation plan is kept up to date and facilitate communications. Therefore, this paper aims to establish a conceptual framework for Dwelling Fire Safety Evacuation (DFSE). The method used for this paper is reviewing literature including journals, conference proceedings, reports and guidelines. The findings of this paper are the components of DSFE conceptual framework which consist of three elements including Fire Scenarios (i.e., design fire and boundary condition), Survival Strategies (i.e., extinguish, shelter and evacuation), and Safety (i.e., shortest time). The conceptual framework is expected to assist in future data collection for the development of the DSFE framework.
\end{abstract}

\section{Introduction}

Since the 1980s, the world has experienced disasters of floods, fire, landslides, volcanic eruption, storm and earthquakes, which causes thousand dead and losses of materials [1]. Fire is known as a significant threat to life and property in urban or rural areas compared to other disasters [2]. The death caused by fire outbreak is mostly high all over the world. As mentioned by Yenumula, Kolmer, Pan, and $\mathrm{Su}$ [1] from 6300 million of world populations in early $21 \mathrm{st}$, the yearly rate of death was 7000 to 80000 with the number of individuals injured caused by the fire was around 5000 to 8000 people.

Fire is a process of start and burning of materials which can produce heat and smoke [3]. Numerous causes of the fire incidents have been highlighted including electrical origins, cooking appliances, faulty or misuse of equipment, careless handling of fire or hot substances (i.e., smoker's materials-careless disposal of cigarettes, cigar or pipe tobacco)( [4]; [5]; [6]).

On the other hand, dwelling is defined as a shelter (i.e., place of residence, house, apartment or accommodation) in which people lives [7] whereby accidental fires include those incidents where the cause was 'not known' or 'unspecified' [8]. Occupants of dwelling houses can ascertain the design intent of their building by ensuring that the elements of design are operated correctly (door are closed and alarm systems are maintained) and that appropriate plans are developed and practiced to ensure safe evacuation from dwelling house in the event of fire [9]. However, according to the Director.

General of Fire and Rescue Department Malaysia, about 6,000 premises are destroyed by fire every year with 40 percent of these involve private houses [10]. As for Malaysia, faulty electrical sources is at the top of the list among all the causes of fire hazard with 877 cases reported in the past seven months besides a total of 457 cases out of the 914 electrical accident cases reported are fatal and $15.5 \%$ of such cases happened at home [11].

In addition, the most critical features of safety in building in fire event is evacuation [12] or opportunity to safely escape from fire [3]. There are three basic activities in the process of evacuation which includes external stimuli of danger awareness, confirmation and reaction to an indicator of danger and move/refuge in a safe place [3]. Delay in the evacuation reaction may cause occupants to be trapped in the dangerous zone [13]. Nonetheless, fire characteristics, building characteristics, and human characteristics are the factors that determine the survival of occupants [14].

\section{Research Methodology}

This research aims to establish a conceptual framework of DFSE. The method used for this paper is through reviewing of literature including journals, conference proceedings, reports and guidelines from the year 2001 to the year 2018. There were 65 papers that have been reviewed, however only 32 papers were selected.

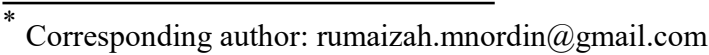




\section{Findings from the review of Literature}

The findings of the existing literature search revealed numerous potential variables to be associated with fire safety evacuation in dwellings including fire scenario and survival strategies in order to reach safety.

\subsection{Fire Scenario}

Fire is defined as a chemical reaction between three elements which known as "fire triangle" that consists of heat, or an ignition source, fuel and oxygen to be present for the reaction to take place and continue [15]. In order to stop a fire, it is necessary to remove one of those elements [16]. As stated by OSHA [15] fire triangle is to help in understanding the sources of fire and how the fire can be extinguished and prevented. According to [17], it is important to identify the type of fire characteristic and classification in order to select the correct method and agent for extinguishing the fire.

\subsubsection{Fire Characteristics}

A fire characteristic may refer to the fire as whole or to a portion of it and any qualitative attribute of a fire which including size, shape, duration, rate of spread, and smoke emission [18]. In addition, the fire characteristic is important towards occupant response due to the different cues that people perceive from the fire and the changes of their behaviour due to the influences of their interpretation to current fire situation [19]. Moreover, the information of fire spread is important to fire evacuation besides serves as an important basis for considering evacuation routes [3].

\subsubsection{Fire Classification}

According to OSHA [15], fire can be classified as based on the category of material that fuels the fire. Table 1 summarises the classification of fire such as Class A, B, $\mathrm{C}, \mathrm{D}$ and $\mathrm{K}$. This classification will help in choosing the most suitable method for extinguishing the fire. in choosing the most suitable method for extinguishing the fire.

Table 1. Classification of Fire

\begin{tabular}{|c|l|}
\hline Class & \multicolumn{1}{c|}{ Material } \\
\hline $\mathrm{A}$ & $\begin{array}{l}\text { Ordinary solid combustibles materials } \\
\text { Example: paper, wood and textile fibres }\end{array}$ \\
\hline $\mathrm{B}$ & $\begin{array}{l}\text { Flammable liquids and gases } \\
\text { Example: gasoline, thinners, oil-based paints } \\
\text { and propane. }\end{array}$ \\
\hline $\mathrm{C}$ & Energized electrical components \\
\hline $\mathrm{D}$ & $\begin{array}{l}\text { Combustible metals } \\
\text { Example: Magnesium, sodium, potassium, } \\
\text { titanium and aluminium }\end{array}$ \\
\hline $\mathrm{K}$ & $\begin{array}{l}\text { Oils and fats } \\
\text { Example: vegetable oils, animal fats }\end{array}$ \\
\hline
\end{tabular}

\subsection{Boundary Conditions}

Figure 1 shows the boundary conditions during a fire which consist of building characteristics and occupant characteristics. According to Zhang \& Issa [20], the evacuation models will be used to simulate the different situation of egress such as building characteristics (i.e. floor numbers and layout of floor) and occupant characteristics (i.e. number of occupants, location of occupants, speed, and body size).

Furthermore, [19] also stated that the occupant behaviour varies according to the three main elements including fire characteristics, building characteristic and occupant characteristics in order to interplay in the whole of development and event outcome.
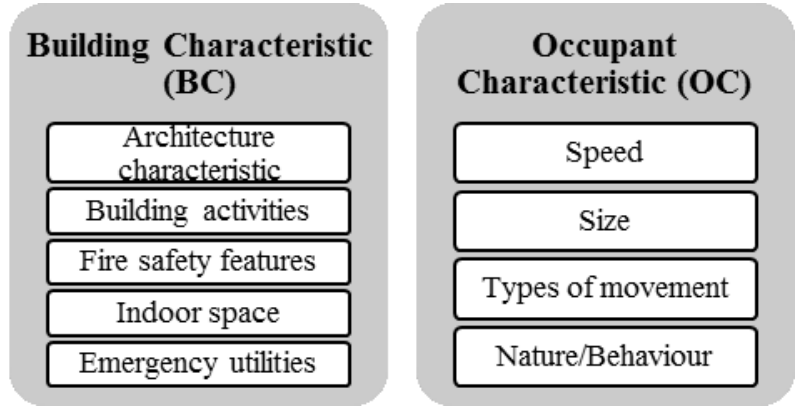

Fig. 1. Boundary condition

\subsubsection{Building Characteristics (BC)}

Building is an infrastructure where people lived need protection against fire outbreak [1] however the lack of facility management and inappropriate guidance poses a risk to the evacuees during fire [1]. According to [21], $\mathrm{BC}$ can be classified by architecture characteristic, building activities and features of fire safety in the building.

Furthermore, there are direct impact of BC during fire outbreak since a building is physically enclosed environment in which people are present and carried out their activities plus consists of information about the building such as information of indoor space, architectural structure and emergency utilities which important to describe accurately the interaction between object of indoor and analysing an evacuation routes of individuals [3]. Hence, $\mathrm{BC}$ is the most important element that needs to be considered in fire safety design [14]. You should leave $35 \mathrm{~mm}$ of space above the title and 6 $\mathrm{mm}$ after the title.

\subsubsection{Characteristic of occupants (OC)}

According to [2] the characteristic elements of building occupants consists of personality traits, position and consciousness, knowledge and experience, power of observation and judgement, power of movement, familiarity with the layout and social features. 


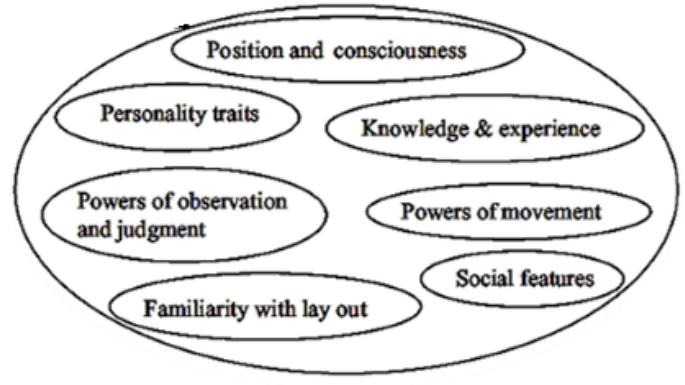

Fig. 2. Behaviour scenario of the building occupants [2].

Besides that, Table 2 shows the characteristics of occupants during a fire which include speed, size, types of movement and occupant nature/behaviour. Authors should use the forms shown in Table 3 in the final reference list.

Table 2. Characteristic of occupant

\begin{tabular}{|c|c|}
\hline Variables & Author \\
\hline Speed & {$[3] ;[20]$} \\
\hline Size & {$[3] ;[20]$} \\
\hline Types of movement & {$[3] ;[13]$} \\
\hline Nature/Behaviour & {$[3] ;[22] ;[1] ;[19]$} \\
\hline
\end{tabular}

According to Kobes, Helsloot, Vries, and Post [3], individuals' speed, types of movement and size are related to the identification of evacuation route. Despite individual is the core element related to behaviour, movement types and size of an individual is related to speed.

Besides that, Grindrod [13] also stated that the movement of occupants through a building is divided into two sections which are horizontal (i.e., escape from any point within a storey to the next storey exit of the floor) and vertical means of escape (i.e., transition from horizontal escape from the building to a place of safety such as protected stairwell or outside the building), with each section, is broken down with the necessary requirement and factors that affect the travel time.

Additionally, the nature of human also has a direct and major influence on the performance of fire response and to analyse this, the behaviour in term of individual characteristic (personal) and group characteristic (social and situational) is been examined [3]. Moreover, unpredictability and complexity of human behaviour is the most influential factor on the success/failure of an evacuation plan because human behaviour and reaction of the human itself to an emergency environment is important however it is still difficult to predict the perspective in the prediction of emergency time and results [22].

Furthermore, the guidance of evacuation system needs to deal with the people that probably have a different individual characteristic. Due to the differences in behaviour and human factor, typically there is still an absence of coordination strategies that can consider human behaviour [22].

Besides that, lack of information provided to the people within the situation about the current conditions often affects the effectiveness of emergency response during incident [13]. It is because the pre-movement behaviour which is defined as the behaviour which occurs before the alarm is sounded and includes the activities which occur between the alarm sounding and the occupants beginning to move towards an exit is believed to be generally more important to survival than the actual movement speed [13]. However, humans regularly tend to be panic as well as create a confused condition during fire accident [1].

\subsection{Survival Strategy}

There are three strategies to survive in a fire which are (try to) extinguish it, take shelter and wait for rescue, and evacuation [3]. However, evacuation is perceived as the most important aspects to save lives [1]. It is because evacuation is the process of rapidly remove people from danger to a safe place as soon as possible [23] due to the aim for survival in the shortest time.

\subsubsection{Fire Evacuation Plan/Guideline}

A fire guideline is about elements that evacuees need to be considered during an emergency evacuation in order to create an evacuation route and achieve an efficient evacuation process [24]. Besides that, wrong choices, panic and hesitation during fire emergency can be reduced by having a proper fire evacuation plan [25]. Hence, the most important for people to evacuate as quickly as possible is the fastest and efficient evacuation [24].

According to Pericleous [25], only people that reviewed and has to participate in emergency drills will able to act calmly and can save property and lives. However, Ismail [26] stated that people are still clueless in the event of a fire or even how to prevent a fire. Hence, the natural or man-made threats and disaster will cause the building evacuation time becomes more important in saving lives during emergency situations [24].

Besides that, evacuation models are key to improve safety performance of the building by allow the engineers and designers to identify the possible solutions of building heavy congestion points in early design stages however if the model is brought into the project when the design is near completion of reaching detailed design phased and a problem has been identified, it may be possible to have an addition of exits or extending means of egress and new stairs [20].

Furthermore, according to Pericleous [25], an important element in fire evacuation plans include fire prevention procedure, preparedness procedure, mitigation procedures, response arrangements and strategies and ECO roles and responsibilities. Therefore, it is important to have a well throughout of fire evacuation plan in order to avoid unnecessary loss of human life [27].

Besides in Figure 3 shows that CDEM [28] of New Zealand has stated there are 11 steps for evacuation planning model which establishes authority to plan, convene planning team, community analysis, review 
hazard and risk assessment, defined planning objective, determine roles and responsibilities, developed plan and establish evacuation management process, document agreed arrangements, exercise and validate the plan, address plan deficiencies and lastly review the plan.

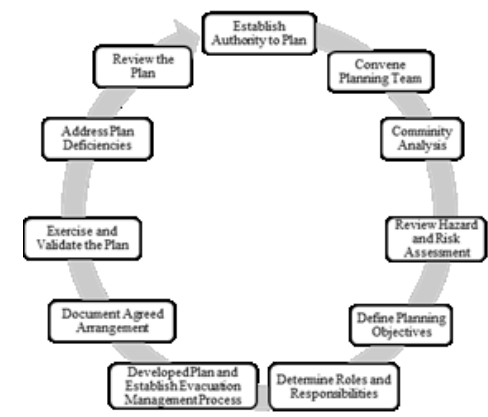

Fig. 3. Evacuation Planning Model

Evacuation modelling able to identify the critical factors that affect the evacuation process under different situation in order to help in reducing evacuation times and avoid critical conditions [29].According to [21], there are six aspects that need to be considered in developing an evacuation model which include times delay, since the individuals do not respond immediately on getting aware of an emergency; speed of walking, condition of crowdedness on a horizontal surface, and up and down stairways; characteristic of occupants, to interpret the different in actions and reaction among different types of people for different types of occupants; evacuation action, since people may increase the time that people take to leave the building; effects to obstruction in travel paths, which can cause delay or block egress; and exit choice decisions, which determine travel path and affect travel times.

Nonetheless, nowadays BIM has been used wisely. The full integration of BIM technology leads to be more intuitive fire evacuation and convenient evacuation drills to direct the rescue more accurately [30]. Besides that, BIM-based model is designed to support fire safety management of the building which can effectively provide 3D geometric data to support the assessment and planning of fire safety (evacuation assessment, escape route planning, and safety education) and it can store information in support of safety management and property management in a web-based environment (using the equipment maintenance module) [14].

\subsection{Safety}

Emergency evacuation is aimed to minimize the total evacuation time of people in the building to avoided serious casualties [31]. This is also agreed by [19] which stated that time delay of evacuation during a fire will cause of risk to life in a building. Evacuation plan that reduces the average total time of evacuation does not necessarily lead to an increased level of safety however the overall exposure to a threat may increase even if the total evacuation time is shorter [29].

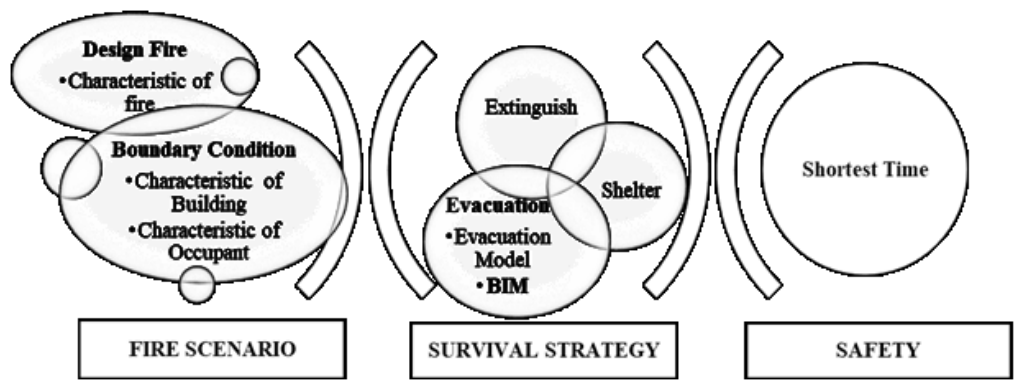

Fig. 4. Proposed Conceptual Research Framework

\section{Proposed Conceptual Research Framework}

A conceptual framework is used to create a conceptual distinction and organize ideas by using an analytical tool that has several variation and contexts [32]. The proposed conceptual framework was constructed based on findings from the literature reviews of previous researchers. The proposed conceptual framework involved the component of DSFE which consists of three (3) components namely Fire Scenarios, Survival Strategies, and Safety.
The first component is Fire Scenarios which consists of Design Fire (i.e. characteristic of fire) and Boundary Condition (Characteristic of building and characteristic of occupancy). The second component is Survival Strategies that consist of extinguishing, shelter and evacuation. Lastly, the third component is Safety (i.e., shortest time). In this framework, BIM technology of building evacuation guidance method has been included to create an effective and scientific dwelling fire evacuation model.

Evacuation modelling will help in allowing a systematic evaluation in a different situation of evacuation and identify the different threats that may 
occur during the evacuation process due to the need for survivaln the shortest time.

\section{Conclusion and recommendation}

This study provided an overview of fire safety evacuation in dwellings. A literature search method was employed, 65 related articles were identified, and 32 were finally included in this review to propose the conceptual framework which consists of three (3) components including Fire Scenarios, Survival Strategies, and Safety. However, in order to strengthen the findings, empirical research is suggested to be carried out.

The research is in conceptual terms which are limited to literature and previous researches that have provided valuable inputs for scholars and practitioners. Future studies can replicate the proposed conceptual framework to become the structural model for statistical analyses, to analyse and confirm the relationships between the elements. The concept is relatively new and has the potential to be developed in future. Therefore in order to achieve the objective of the research, the prospect of the respondent will be from the Fire and Rescue Department, Ministry of Urban Wellbeing, Housing and Local Government and survival of ADF.

The authors would like to thank Bestari Perdana Research Grant from Universiti Teknologi MARA, Malaysia (File No: 600-IRMI/DANA 5/3 BESTARI (P) (023/2018) for supporting this research.

\section{References}

1. K. Yenumula, C. Kolmer, J. Pan and X. Su, "BIM-Controlled Signage System for Building Evacuation," in International Conference on Sustainable Design, Engineering and Construction, (2015)

2. J. Xin and C. Huang, "Fire risk analysis of residential buildings based on scenario clusters and its application in fire risk management," Fire Safety Journal, 62, 72-78 (2013)

3. M. Kobes, I. Helsloot, B. D. Vries and J. G. Post, "Building SAfety and Human Behaviour in Fire: A Literature Review," Fire Safety Journal, 45(1), 1-11 (2010)

4. Crown, "Fire Statistics, United Kingdom, 2008," (2010) [Online]. Available: https://assets.publishing.service.gov.uk/govern ment/uploads/system/uploads/attachment_dat a/file/11746/Fire_Statistics_United_Kingdom_ 2008.pdf. [Accessed 4 July 2018].

5. V. Babrauskas, "Some Neglected Areas in Fire Safety Engineering," Fire Science and Technology, 32(1), 35-48 (2013)

6. M.S. Rahim, "The Current Trends and Challenging Situations of Fire Incidents
Statistics," Malaysian Journal of Forensic Science, 6(1), 63-78 (2015)

7. Merriam-Webster, "Dwelling," 2018. [Online]. Available: https://www.merriamwebster.com/dictionary/dwelling. [Accessed 24 May 2018].

8. Crown, "Fire Statistics United Kingdom," Department for Communities and Local Government, London (2007)

9. EOBA, "Framework for Enhancing Fire Safety in Dwellings where concerns arise," Eamon O'Boyle and Associates (2017)

10. M. Muhamading, "About 6,000 premises destroyed by fire annually in Malaysia," 28 September 2016. [Online]. Available: https://www.nst.com.my/news/2016/09/17660 7/about-6000-premises-destroyed-fire-annuallymalaysia. [Accessed 3 October 2017].

11. I. Hannah, "Faulty electrical sources top list as the cause of fires," Star Online Website, December 2017. [Online]. Available: https://www.thestar.com.my/metro/metronews/2017/12/02/faulty-electrical-sources-toplist-as-cause-of-fires-authorities-warn-againstusing-imitation-gadget/. [Accessed 2 July 2018].

12. M.T. Kinateder, E. Kuligowski, P. Reneke and R. Peacock, "Risk Perception in Fire Evacuation Behaviour Revisited: Definitions, related concepts, and empirical evidence," Fire Science Review, 4(1), 2-26 (2015)

13. S. E. Grindrod, "Information Driven Evacuation System (I.D.E.S)," The University of Edinburgh, United Kingdom (2014)

14. S. H. Wang, W. C. Wang, K. C. Wang and S. Y. Shih, "Applying building information modeling to support fire safety management," Automation in Construction, 59, 158-167 (2015)

15. OSHA, "Fire Protection and Prevention," 2018. [Online]. Available: https://www.osha.gov/dte/grant_materials/fy09 /sh-18796-09/fireprotection.pdf. [Accessed 16 May 2018]. M. Ben Rabha, M.F. Boujmil, M. Saadoun, B. Bessaïs, Eur. Phys. J. Appl. Phys. (to be published)

16. Luigi T. De Luca, Propulsion physics (EDP Sciences, Les Ulis, 2009)

17. F. De Lillo, F. Cecconi, G. Lacorata, A. Vulpiani, EPL, 84 (2008)

18. J. Scott, "Fire Characteristic," August 2007. [Online]. Available: http://firewords.net/definitions/fire_characterist ics.htm. [Accessed 17 May 2018]. 
19. G. Proulx, "Occupant Behaviour and Evacuation," in Proceedings of the 9th International Fire Protection Symposium, Munich, 2001.

20. J. Zhang and R. R. A. Issa, "Collecting Fire Evacuation Performance Data Using BIM-Based Immersive Serious Games for PerformanceBased Fire Safety Design," in Computing in Civil Engineering, Shah Alam (2015)

21. L. Shi, Q. Xie, X. Cheng, L. Chen, Y. Zhou and R. Zhang, "Developing a database for emergency evacuation model," Bulding and Environment, 44, 1724-1729 (2009)

22. R. Liu, J. Du and R. R. Issa, "Human Library for Emergency Evacuation in BIM-Based Serious Game Environment," in 2014 International Conference on Computing in Civil and Building Engineering (2014)

23. Fire and Rescue NSW, "Evacuation," 2018. [Online]. Available: https://www. fire.nsw.gov.au/page.php?id=75. [Accessed 22 May 2018].

24. M. Lujak, H. Billhardt, J. Dunkel, A. Fernandez, R. Hermoso and S. Ossowski, A Distributed Architecture for Real Time Evacuation Guidance in Large Smart Buildings, Hochschule Hannover, 257-282 (2017)

25. A. Pericleous, "How a fire evacuation plan can save lives," 2015. [Online]. Available: http://www.firesafeservices.com.au/firesafe/ho w-a-fire-evacuation-plan-can-save-lives. [Accessed 18 May 2018].

26. Z. Ismail, "Fire SAfety SAves Lives," January 2018. [Online]. Available: https://mypositiveparenting.org/2018/01/21/fir e-safety-saves-lives/. [Accessed 18 May 2018].

27. A. Stancik, R. Machacek and J. Horak, "Using BIM model for Fire Emergency Evacuation Plan," in MATEC Web of Conferences 146, 2018.

28. CDEM, "Mass Evacuation Planning," June 2008. [Online]. Available: https://www.civildefence.govt.nz/assets/Uploa ds/publications/dgl-07-08-mass-evacuationplanning.pdf. [Accessed 27 June 2018].

29. E. Ronchi, F.N. Uriz, X. Criel and P. Reilly, "Modelling Large Scale Evacuation of Music Festivals," Case Studies in Fire Safety, 5, 11-19 (2016)

30. J. Ma, W. Jia and J. Zhang, "Research of building evacuation path to guide based on BIM," in Control and Decision Conference (CCDC) 2017 29th Chinese, Chongqing, 2017.

31. C. Liu, Z. L. Mao and Z. M. Fu, "Emergency Evacuation Model and Algotithm in the Building with several exits," in 2015 International
Conference on Performance-based Fire and Fire Protection Engineering (ICPFFPE 2015), 2016.

32. R. Yacob, M. Saruwono and Z. Ismail, "The Influence of Human Impact Factor on the Uncertainty of Refurbishment Projects:A Conceptial Approach," Journal of Building Performance, 8(1), 69-79 (2017) 